\title{
Evolutionary diversification and characterization of the eubacterial gene family encoding DXR type II, an alternative isoprenoid biosynthetic enzyme
}

\author{
Lorenzo Carretero-Paulet ${ }^{1,2^{*}}$, Agnieszka Lipska ${ }^{1}$, Jordi Pérez-Gil ${ }^{3}$, Félix J Sangari ${ }^{4}$, Victor A Albert ${ }^{1}$
} and Manuel Rodríguez-Concepción ${ }^{3^{*}}$

\begin{abstract}
Background: Isoprenoids constitute a vast family of natural compounds performing diverse and essential functions in all domains of life. In most eubacteria, isoprenoids are synthesized through the methylerythritol 4-phosphate (MEP) pathway. The production of MEP is usually catalyzed by deoxyxylulose 5-phosphate reductoisomerase (DXR-I) but a few organisms use an alternative DXR-like enzyme (DXR-II).

Results: Searches through 1498 bacterial complete proteomes detected 130 sequences with similarity to DXR-II. Phylogenetic analysis identified three well-resolved clades: the DXR-II family (clustering 53 sequences including eleven experimentally verified as functional enzymes able to produce MEP), and two previously uncharacterized NAD(P)-dependent oxidoreductase families (designated DLO1 and DLO2 for DXR-II-like oxidoreductases 1 and 2). Our analyses identified amino acid changes critical for the acquisition of DXR-II biochemical function through type-I functional divergence, two of them mapping onto key residues for DXR-II activity. DXR-II showed a markedly discontinuous distribution, which was verified at several levels: taxonomic (being predominantly found in Alphaproteobacteria and Firmicutes), metabolic (being mostly found in bacteria with complete functional MEP pathways with or without DXR-I), and phenotypic (as no biological/phenotypic property was found to be preferentially distributed among DXR-II-containing strains, apart from pathogenicity in animals). By performing a thorough comparative sequence analysis of GC content, 3:1 dinucleotide frequencies, codon usage and codon adaptation indexes (CAI) between DXR-II sequences and their corresponding genomes, we examined the role of horizontal gene transfer (HGT), as opposed to an scenario of massive gene loss, in the evolutionary origin and diversification of the DXR-II subfamily in bacteria.

Conclusions: Our analyses support a single origin of the DXR-II family through functional divergence, in which constitutes an exceptional model of acquisition and maintenance of redundant gene functions between nonhomologous genes as a result of convergent evolution. Subsequently, although old episodic events of HGT could not be excluded, the results supported a prevalent role of gene loss in explaining the distribution of DXR-II in specific pathogenic eubacteria. Our results highlight the importance of the functional characterization of evolutionary shortcuts in isoprenoid biosynthesis for screening specific antibacterial drugs and for regulating the production of isoprenoids of human interest.
\end{abstract}

Keywords: DXR-II, Isoprenoid metabolism, Horizontal gene transfer, Gene loss, Functional divergence

\footnotetext{
*Correspondence: lorenzoc@buffalo.edu; manuel.rodriguez@cragenomica.es ${ }^{1}$ Institute for Plant Molecular and Cell Biology - IBMCP (CSIC-UPV), Integrative Systems Biology Group, C/ Ingeniero Fausto Elio s/n., Valencia 46022, Spain ${ }^{3}$ Centre for Research in Agricultural Genomics (CRAG), CSIC-IRTA-UAB-UB,

Campus UAB, Bellaterra, Barcelona 08193, Spain

Full list of author information is available at the end of the article
} 


\section{Background}

Isoprenoids constitute the largest family of natural compounds both at a structural and functional level [1-3]. They are found in all the three domains of life (bacteria, archaea, and eukaryotes). Despite their diversity in structures and functions, all isoprenoids derive from the common five-carbon precursors isopentenyl diphosphate (IPP) and its isomer dimethylallyl diphosphate (DMAPP). IPP can be synthesized through two independent metabolic pathways, the mevalonate (MVA) pathway, or the more recently elucidated methylerythritol 4-phosphate (MEP) pathway [4] (Figure 1). In most eubacteria, isoprenoids are synthesized through the MEP pathway, while a few species use the MVA pathway, both pathways, or none, the latter obtaining their isoprenoids from host cells [5-8]. Previous analysis suggested that eukaryotes have inherited MEP and MVA pathways genes from eubacteria and archaebacteria, respectively, as reflected by their phylogenetic distribution [5]. In plants, plastidial IPP and DMAPP are synthesized through the MEP pathway, whereas cytosolic and mitochondrial isoprenoids are synthesized through the MVA pathway [4,9]. Non-photosynthetic simpler plastid-bearing organisms, such as the apicomplexan protists, solely use the MEP pathway [10]. In contrast, in yeast and animals, all isoprenoids are synthesized through the
MVA pathway [11]. The lack of MEP pathway enzymes in non-plastid bearing eukaryotes suggests that these genes were acquired through gene transfer to the nucleus from the eubacterial endosymbiotic ancestors that gave rise to plastids [5,12].

Isoprenoids are essential in all eubacteria in which they have been studied, playing key roles in several core cellular functions e.g. ubiquinones and menaquinones, which act as electron carriers of the aerobic and anaerobic respiratory chains respectively, and dolichols, which are required for cell wall peptidoglycan synthesis [13]. Because of the essential role of the MEP pathway in most eubacteria and its absence from animals, it has been proposed as a promising new target for the development of novel antibiotics $[14,15]$. Besides that, many isoprenoids also have substantial industrial, pharmacological, and nutritional interest [16]. Therefore, understanding the biochemical and genetic plasticity of isoprenoid biosynthesis in bacteria is crucial to attempt its pharmacological block or to be used in biofactories for the production of isoprenoids of human interest.

The occurrence of alternative enzymes for isoprenoid biosynthesis in specific bacterial lineages has been previously reported [17]. The enzyme 3-hydroxy-3-methylglutaryl-CoA reductase (HMGR), which catalyzes the
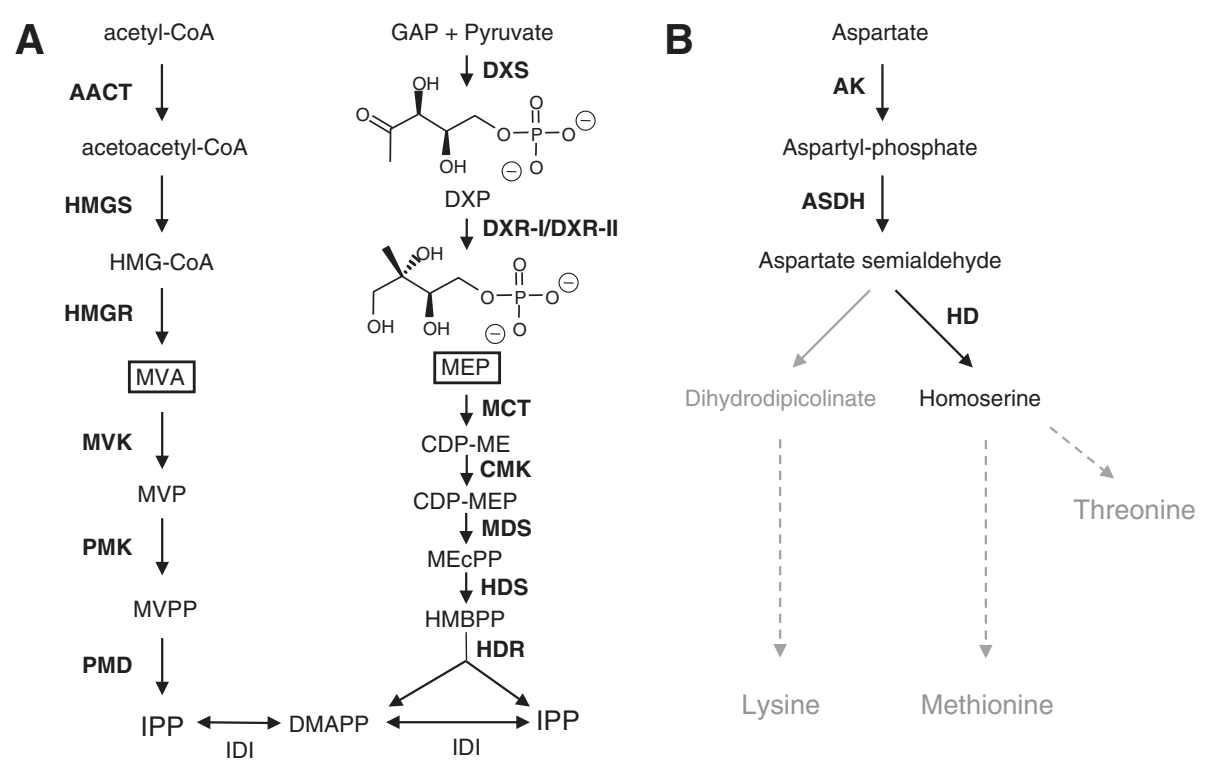

Figure 1 Isoprenoid and amino acid biosynthetic pathways. A) Pathways for the biosynthesis of isoprenoid precursors. On the left, MVA pathway is represented. Enzymes are indicated in bold: AACT, acetoacetyl-CoA thiolase; HMGS, HMG-CoA synthase; HMGR, HMG-CoA reductase; MVK, mevalonate kinase; PMVK, 5-phosphomevalonate kinase; DPMD, 5-diphosphomevalonate decarboxylase; IDI, IPP/DMAPP isomerase. On the right, MEP pathway steps are described: GAP, D-glyceraldehyde 3-phosphate; DXP, 1-deoxy-D-xylulose 5-phosphate; MEP, 2-C-methyl-D-erythritol 4-phosphate; CDP-ME,4-diphosphocytidyl-2-C-methyl-D-erythritol; MEcPP, 2-C-methyl-D-erythritol 2,4-cyclodiphosphate; HMBPP, 4-hydroxy-3methylbut-2-enyl diphosphate; IPP, isopentenyl diphosphate; DMAPP, dimethylallyl diphosphate. Enzymes are indicated in bold: DXS, DXP synthase; DXR, DXP reductoisomerase; MCT, MEP cytidylyltransferase; CMK, CDPME kinase; MDS, ME-cPP synthase; HDS, HMBPP synthase; HDR, HMBPP reductase; IDI, IPP isomerase. B) Amino acid biosynthesis. The common pathway (CP) is highlighted in black and enzymes indicated in bold: AK, aspartokinase; ASDH, aspartate semialdehyde dehydrogenase; HD, homoserine dehydrogenase. Solid arrows indicate single catalytic steps and dashed arrows mark multiple steps. 
rate-limiting step of the MVA pathway, is structurally distant from its archaebacterial and eukaryotic homologs in most eubacteria $[8,18,19]$. Similarly, two different classes of isopentenyl diphosphate isomerase (IDI), the enzyme catalyzing the isomerization of IPP to produce DMAPP, have been identified in bacteria: type I IDI (similar to its animal, fungi and plant counterparts) and type II IDI, acquired from archaebacteria and apparently unrelated to the latter [20-22]. Although IDI activity is only essential in organisms dependent on the MVA pathway for IPP and isoprenoid biosynthesis, both types of IDI have been identified in bacterial strains dependent on the MEP pathway [7].

We recently reported the occurrence of a group of bacteria harbouring the entire set of enzymes of the MEP pathway with the exception of 1-deoxy-d-xylulose 5-phosphate (DXP) reductoisomerase (DXR), the enzyme catalyzing the NADPH-dependent production of MEP from DXP in the first committed step of the pathway. In these species, a novel family of previously uncharacterized oxidoreductases related to homoserine dehydrogenases (HD) involved in the common pathway (CP) of amino acid biosynthesis (Figure 1), was found to perform the DXR biochemical reaction [23]. This alternative enzyme, referred to as DXR-like (DRL) or DXR type II (DXR-II) to distinguish it from the canonical DXR (renamed DXR-I), displayed a markedly discontinuous distribution. DXR-II was found forming single or multigene families in bacterial strains from diverse taxonomic groups, independent of the presence or absence of a DXR-I sequence in their genome [23].

Different evolutionary scenarios might explain DXR-II emergence and evolutionary diversification. In this study we examined how the DXR-II family emerged through functional divergence from related oxidoreductase families and identified amino acid changes critical for the acquisition of its specific biochemical function. Furthermore, we assess the contrasting roles of horizontal gene transfer (HGT) and massive gene loss, major forces in microbial genome evolution known to affect other genes involved in IPP and isoprenoid biosynthesis [24], in the discontinuous distribution of DXR-II across eubacteria.

\section{Results}

DXR-Ils cluster into a single clade closely related to two uncharacterized oxidoreductase families

The complete proteomes of 1489 eubacterial strains were screened for the occurrence of DXR-II sequences using the protein sequence from Brucella melitensis biovar abortus 2308 DXR-II (formerly Brucella abortus 2308, gene id: 83269188) as a query [23]. To reduce false positives caused by hits corresponding to distantly related sequences, we applied a best reciprocal hit criterion i.e. orthology was assumed only if two genes in each different genome are each other's best hit [25]. Indeed, eight sequences were not confirmed as reciprocal best hits, including two identified in a previous survey conducted following a unidirectional BLAST search approach [23], and these were consequently discarded from further analyses. 128 sequence hits were identified in as many bacterial strains (Table 1), belonging to a wide variety of the main bacterial taxonomic groups (Figure 2). Among these, two bacterial strains (Mesorhizobium loti MAFF303099 and Ochrobactrum anthropi ATCC 49188) had been previously shown to code for additional functional DXR-II paralogs [23] that were not identified by our analysis, specifically designed to identify co-orthologs in genome wide scans, but were added to the final dataset (Table 1).

Using the amino acid sequence alignment of the resulting full dataset of 130 hits (Additional file 1), a maximum likelihood (ML) phylogenetic analysis was performed (Figure 2 and Additional file 2). Alternative methods of phylogenetic inference (Bayesian -Additional file 3- and neighbor joining -Additional file 4) were also implemented, resulting in trees with almost identical topologies (unpublished data). Three main clades were consistently retrieved with high support values (Figure 2). A clade grouping 53 sequences, including 11 encoding for functional DXR-II as shown in complementation assays in [23] and Additional file 5, was designated as the DXR-II family and likely corresponds to actual DXR-II sequences (Figure 2). The remaining 77 sequences cluster into two additional clades and might not be true functional DXR-II sequences (Figure 2). As such, these were tentatively designated DLO1 and DLO2, for DXR-II-Like 1 and 2 Oxidoreductases. Indeed, four representative sequences belonging to the DLO1 and 2 families had also been previously tested for DXR-II activity, failing to complement the DXR defective mutant (Figure 2) [23].

DXR-II and DLO sequences showed similarity to NAD (P)-dependent oxidoreductases, and particularly to HD enzymes, at a sequence [23] and structural level [26]. Correspondingly, searches for INTERPRO functional domains identified the NAD-binding domain with a core Rossmann-type fold at the N-terminal region of every single protein sequence (domain 1; Figure 2). Up to five additional domains could also be found in DXR-II and DLO proteins. To examine whether these protein domains were differentially distributed across the DXR-II, DLO1, and DLO2 families, we mapped the architecture of protein domains onto the corresponding tree (Figure 2). Most sequences from the DXR-II family shared NAD-binding (domain 1) and SAF (domain 6) domains, while a significant fraction also included N-terminal NAD/NADP-binding domains of aspartate/homoserine dehydrogenase (domain 2). However, no common domain architecture 
Table 1 List of DXR-II and DLO related sequences examined in this study

\begin{tabular}{|c|c|c|c|c|c|c|c|}
\hline & Bacterial strain & UID & GenBank and RefSeq & & Bacterial strain & UID & GenBank and RefSeq \\
\hline \multirow[t]{20}{*}{ DXR-II } & $\begin{array}{l}\text { Anaerococcus prevotii } \\
\text { DSM } 20548\end{array}$ & 59219 & gi|257066990|ref|YP_003153246.1 & DL01 & Frankia sp. Eullc & 42615 & gi|312199021|ref|YP_004019082.1 \\
\hline & Bacillus clausii KSM-K16 & 58237 & gi|56965002|ref|YP_176733.1 & & $\begin{array}{l}\text { Gloeobacter violaceus } \\
\text { PCC } 7421\end{array}$ & 58011 & gi|37521773|ref|NP_925150.1 \\
\hline & $\begin{array}{l}\text { Bacillus halodurans } \\
\text { C-125 }\end{array}$ & 57791 & gi|15613337|ref|NP_241640.1 & & $\begin{array}{l}\text { Hirschia baltica } \\
\text { ATCC } 49814\end{array}$ & 59365 & gi|254294497|ref|YP_003060520.1 \\
\hline & $\begin{array}{l}\text { Bacillus pumilus } \\
\text { SAFR-032 }\end{array}$ & 59017 & gi|157692210|ref|YP_001486672.1 & & $\begin{array}{l}\text { Kineococcus } \\
\text { radiotolerans SRS30216 }\end{array}$ & 58067 & gi|152964541|ref|YP_001360325.1 \\
\hline & $\begin{array}{l}\text { Bartonella bacilliformis } \\
\text { KC583 }\end{array}$ & 58533 & gi|121601844|ref|YP_989368.1 & & $\begin{array}{l}\text { Methanosphaerula } \\
\text { palustris E1-9c }\end{array}$ & 59193 & gi|219852978|ref|YP_002467410.1 \\
\hline & $\begin{array}{l}\text { Bartonella clarridgeiae } \\
73\end{array}$ & 62131 & gi|319898668|ref|YP_004158761.1 & & $\begin{array}{l}\text { Nakamurella } \\
\text { multipartita DSM } 44233\end{array}$ & 59221 & gi|258653356|ref|YP_003202512.1 \\
\hline & $\begin{array}{l}\text { Bartonella grahamii } \\
\text { astaup }\end{array}$ & 59405 & gi|240851045|ref|YP_002972445.1 & & Nostoc azollae 0708 & 49725 & gi|298491811|ref|YP_003721988.1 \\
\hline & $\begin{array}{l}\text { Bartonella henselae } \\
\text { str. Houston-1 }\end{array}$ & 57745 & gi|49475991|ref|YP_034032.1 & & $\begin{array}{l}\text { Nostoc punctiforme } \\
\text { PCC } 73102\end{array}$ & 57767 & gi|186681545|ref|YP_001864741.1 \\
\hline & $\begin{array}{l}\text { Bartonella quintana } \\
\text { str. Toulouse }\end{array}$ & 57635 & gi|49474558|ref|YP_032600.1 & & Nostoc sp. PCC 7120 & 57803 & gi|17230323|ref|NP_486871.1 \\
\hline & $\begin{array}{l}\text { Bartonella tribocorum } \\
\text { CIP } 105476\end{array}$ & 59129 & gi|163868831|ref|YP_001610057.1 & & $\begin{array}{l}\text { Pseudomonas stutzeri } \\
\text { A1501 }\end{array}$ & 58641 & gi|146282531|ref|YP_001172684.1 \\
\hline & $\begin{array}{l}\text { Brucella abortus } \\
\text { bv. } 1 \text { str. } 9-941\end{array}$ & 58019 & gi|62317206|ref|YP_223059.1 & & $\begin{array}{l}\text { Pseudomonas stutzeri } \\
\text { ATCC } 17588=\text { LMG } 11199\end{array}$ & 68749 & gi|339494143|ref|YP_004714436.1 \\
\hline & Brucella abortus S19 & 58873 & gi|189022468|ref|YP_001932209.1 & & $\begin{array}{l}\text { Pseudoxanthomonas } \\
\text { spadix BD-a59 }\end{array}$ & 75113 & gi|357416048|ref|YP_004929068.1 \\
\hline & $\begin{array}{l}\text { Brucella canis ATCC } \\
23365\end{array}$ & 59009 & gi|161621022|ref|YP_001594908.1 & & $\begin{array}{l}\text { Ramlibacter } \\
\text { tataouinensis TTB310 }\end{array}$ & 68279 & gi|337280130|ref|YP_004619602.1 \\
\hline & $\begin{array}{l}\text { Brucella melitensis ATCC } \\
23457\end{array}$ & 59241 & gi|225686729|ref|YP_002734701.1 & & $\begin{array}{l}\text { Rhodobacter } \\
\text { sphaeroides } 2.4 .1\end{array}$ & 57653 & gi|77463590|ref|YP_353094.1 \\
\hline & $\begin{array}{l}\text { Brucella melitensis } \\
\text { biovar Abortus } 2308\end{array}$ & 62937 & gi|83269188|ref|YP_418479.1 & & $\begin{array}{l}\text { Rhodobacter } \\
\text { sphaeroides ATCC } 17025\end{array}$ & 58451 & gi|146278215|ref|YP_001168374.1 \\
\hline & $\begin{array}{l}\text { Brucella melitensis } \\
\text { bv. } 1 \text { str. } 16 \mathrm{M}\end{array}$ & 57735 & gi|17988671|ref|NP_541304.1 & & $\begin{array}{l}\text { Rhodobacter } \\
\text { sphaeroides ATCC } 17029\end{array}$ & 58449 & gi|126462422|ref|YP_001043536.1 \\
\hline & $\begin{array}{l}\text { Brucella microti CCM } \\
4915\end{array}$ & 59319 & gi|256015731|ref|YP_003105740.1 & & $\begin{array}{l}\text { Rhodobacter } \\
\text { sphaeroides KD131 }\end{array}$ & 59277 & gi|221639432|ref|YP_002525694.1 \\
\hline & $\begin{array}{l}\text { Brucella ovis } \\
\text { ATCC } 25840\end{array}$ & 58113 & gi|148558391|ref|YP_001257886.1 & & $\begin{array}{l}\text { Rhodothermus marinus } \\
\text { DSM } 4252\end{array}$ & 41729 & gi|268316714|ref|YP_003290433.1 \\
\hline & $\begin{array}{l}\text { Brucella pinnipedialis } \\
\text { B2/94 }\end{array}$ & 71131 & gi|340792737|ref|YP_004758201.1 & & $\begin{array}{l}\text { Rhodothermus marinus } \\
\text { SG0.5JP17-172 }\end{array}$ & 72767 & gi|345303494|ref|YP_004825396.1 \\
\hline & Brucella suis 1330 & 57927 & gi|23500696|ref|NP_700136.1 & & $\begin{array}{l}\text { Sphingomonas } \\
\text { wittichii } R W 1\end{array}$ & 58691 & gi|148557435|ref|YP_001265017.1 \\
\hline
\end{tabular}


Table 1 List of DXR-II and DLO related sequences examined in this study (Continued)

\begin{tabular}{|c|c|c|c|c|c|c|}
\hline $\begin{array}{l}\text { Brucella suis ATCC } \\
23445\end{array}$ & 59015 & gi|163845083|ref|YP_001622738.1 & & $\begin{array}{l}\text { Streptomyces griseus } \\
\text { subsp. griseus NBRC } \\
13350\end{array}$ & 58983 & gi|182439707|ref|YP_001827426.1 \\
\hline Chelativorans sp. BNC1 & 58069 & gi|1 10636013|ref|YP_676221.1 & & $\begin{array}{l}\text { Xanthomonas } \\
\text { campestris pv. } \\
\text { campestris str. } 8004\end{array}$ & 57595 & gi|77761197|ref|YP_243248.2 \\
\hline $\begin{array}{l}\text { Chloroflexus } \\
\text { aurantiacus J-10-fl }\end{array}$ & 57657 & gi|163846900|ref|YP_001634944.1 & & $\begin{array}{l}\text { Xanthomonas } \\
\text { campestris pv. } \\
\text { campestris str. ATCC } \\
33913\end{array}$ & 57887 & gi|77747863|ref|NP_637377.2 \\
\hline Chloroflexus sp. Y-400-fl & 59085 & gi|222524722|ref|YP_002569193.1 & & $\begin{array}{l}\text { Xanthomonas } \\
\text { campestris pv. } \\
\text { campestris str. B100 }\end{array}$ & 61643 & gi|188991706|ref|YP_001903716.1 \\
\hline Clostridium difficile 630 & 57679 & gi|126700028|ref|YP_001088925.1 & DLO2 & $\begin{array}{l}\text { Achromobacter } \\
\text { xylosoxidans A8 }\end{array}$ & 59899 & gi|311109080|ref|YP_003981933.1 \\
\hline $\begin{array}{l}\text { Clostridium difficile } \\
\text { CD196 }\end{array}$ & 41017 & gi|260683992|ref|YP_003215277.1 & & $\begin{array}{l}\text { Acidiphilium cryptum } \\
\text { JF-5 }\end{array}$ & 58447 & gi|148260557|ref|YP_001234684.1 \\
\hline $\begin{array}{l}\text { Clostridium difficile } \\
\text { R20291 }\end{array}$ & 40921 & gi|260687652|ref|YP_003218786.1 & & $\begin{array}{l}\text { Acidiphilium } \\
\text { multivorum }\end{array}$ & 63345 & gi|326403752|ref|YP_004283834.1 \\
\hline $\begin{array}{l}\text { Eubacterium limosum } \\
\text { KIST612 }\end{array}$ & 59777 & gi|310828050|ref|YP_003960407.1 & & Acidovorax ebreus TPSY & 59233 & gi|222110742|ref|YP_002553006.1 \\
\hline $\begin{array}{l}\text { Finegoldia magna ATCC } \\
29328\end{array}$ & 58867 & gi|169824217|ref|YP_001691828.1 & & Acidovorax sp. JS42 & 58427 & gi|121594656|ref|YP_986552.1 \\
\hline $\begin{array}{l}\text { Halanaerobium } \\
\text { hydrogeniformans }\end{array}$ & 60191 & gi|312144614|ref|YP_003996060.1 & & $\begin{array}{l}\text { Actinosynnema mirum } \\
\text { DSM } 43827\end{array}$ & 58951 & gi|256377798|ref|YP_003101458.1 \\
\hline $\begin{array}{l}\text { Listeria innocua } \\
\text { Clip11262 }\end{array}$ & 61567 & gi|16799625|ref|NP_469893.1 & & $\begin{array}{l}\text { Agrobacterium } \\
\text { sp. H13-3 }\end{array}$ & 63403 & gi|332715931|ref|YP_004443397.1 \\
\hline Listeria ivanovii & 73473 & gi|347547952|ref|YP_004854280.1 & & $\begin{array}{l}\text { Agrobacterium } \\
\text { tumefaciens str. C58 }\end{array}$ & 57865 & gi|15891768|ref|NP_357440.1 \\
\hline Listeria monocytogenes & 43671 & gi|284800826|ref|YP_003412691.1 & & $\begin{array}{l}\text { Anaeromyxobacter } \\
\text { sp. Fw109-5 }\end{array}$ & 58755 & gi|153005951|ref|YP_001380276.1 \\
\hline $\begin{array}{l}\text { Listeria monocytogenes } \\
08-5923\end{array}$ & 43727 & gi|284994012|ref|YP_003415780.1 & & Arthrobacter sp. FB24 & 58141 & gi|1 16672147|ref|YP_833080.1 \\
\hline $\begin{array}{l}\text { Listeria monocytogenes } \\
\text { EGD-e }\end{array}$ & 61583 & gi|16802589|ref|NP_464074.1 & & $\begin{array}{l}\text { Azorhizobium } \\
\text { caulinodans ORS } 571\end{array}$ & 58905 & gi|158423518|ref|YP_001524810.1 \\
\hline $\begin{array}{l}\text { Listeria monocytogenes } \\
\text { HCC23 }\end{array}$ & 59203 & gi|217965360|ref|YP_002351038.1 & & Bordetella avium $197 \mathrm{~N}$ & 61563 & gi|187476836|ref|YP_784860.1 \\
\hline $\begin{array}{l}\text { Listeria monocytogenes } \\
\text { serotype } 4 b \text { str. CLIP } \\
80459\end{array}$ & 59317 & gi|226223175|ref|YP_002757282.1 & & $\begin{array}{l}\text { Bordetella } \\
\text { bronchiseptica RB50 }\end{array}$ & 57613 & gi|33599421|ref|NP_886981.1 \\
\hline $\begin{array}{l}\text { Listeria monocytogenes } \\
\text { serotype } 4 b \text { str. F } 2365\end{array}$ & 57689 & gi|46906791|ref|YP_013180.1 & & $\begin{array}{l}\text { Bordetella parapertussis } \\
12822\end{array}$ & 57615 & gi|33595139|ref|NP_882782.1 \\
\hline
\end{tabular}


Table 1 List of DXR-II and DLO related sequences examined in this study (Continued)

\begin{tabular}{|c|c|c|c|c|c|c|}
\hline & $\begin{array}{l}\text { Listeria welshimeri } \\
\text { serovar } 6 b \text { str. SLCC5334 }\end{array}$ & 61605 & gi|116871936|ref|YP_848717.1 & $\begin{array}{l}\text { Bordetella petrii DSM } \\
12804\end{array}$ & 61631 & gi|163858833|ref|YP_001633131.1 \\
\hline & $\begin{array}{l}\text { Mesorhizobium ciceri } \\
\text { biovar biserrulae } \\
\text { WSM1271 }\end{array}$ & 62101 & gi|319781195|ref|YP_004140671.1 & $\begin{array}{l}\text { Bradyrhizobium } \\
\text { japonicum USDA } 110\end{array}$ & 57599 & gi|27382926|ref|NP_774455.1 \\
\hline & $\begin{array}{l}\text { Mesorhizobium loti } \\
\text { MAFF303099 (1) }\end{array}$ & 57601 & gi|13473132|ref|NP_104699.1 & $\begin{array}{l}\text { Bradyrhizobium } \\
\text { sp. BTAi1 }\end{array}$ & 58505 & gi|148252763|ref|YP_001237348.1 \\
\hline & $\begin{array}{l}\text { Mesorhizobium loti } \\
\text { MAFF303099 (2) }\end{array}$ & 57601 & gi|13475431|ref|NP_106995.1 & $\begin{array}{l}\text { Bradyrhizobium } \\
\text { sp. ORS278 }\end{array}$ & 58941 & gi|146343223|ref|YP_001208271.1 \\
\hline & $\begin{array}{l}\text { Mesorhizobium } \\
\text { opportunistum } \\
\text { WSM2075 }\end{array}$ & 40861 & gi|337266026|ref|YP_004610081.1 & $\begin{array}{l}\text { Candidatus Pelagibacter } \\
\text { ubique HTCC1062 }\end{array}$ & 58401 & gi|71083552|ref|YP_266271.1 \\
\hline & $\begin{array}{l}\text { Ochrobactrum anthropi } \\
\text { ATCC } 49188 \text { (1) }\end{array}$ & 58921 & gi|153008718|ref|YP_001369933.1 & Cupriavidus necator $\mathrm{N}-1$ & 68689 & gi|339328796|ref|YP_004688488.1 \\
\hline & $\begin{array}{l}\text { Ochrobactrum anthropi } \\
\text { ATCC } 49188 \text { (2) }\end{array}$ & 58921 & gi|153011435|ref|YP_001372649.1 & Cupriavidus taiwanensis & 61615 & gi|194292943|ref|YP_002008850.1 \\
\hline & $\begin{array}{l}\text { Pelagibacterium } \\
\text { halotolerans B2 }\end{array}$ & 74393 & gi|357386128|ref|YP_004900852.1 & $\begin{array}{l}\text { Methylibium } \\
\text { petroleiphilum PM1 }\end{array}$ & 58085 & gi|124268433|ref|YP_001022437.1 \\
\hline & $\begin{array}{l}\text { Roseobacter litoralis } \\
\text { Och } 149\end{array}$ & 54719 & gi|339504759|ref|YP_004692179.1 & $\begin{array}{l}\text { Methylobacterium } \\
\text { nodulans ORS } 2060\end{array}$ & 59023 & gi|220926646|ref|YP_002501948.1 \\
\hline & $\begin{array}{l}\text { Sebaldella termitidis } \\
\text { ATCC } 33386\end{array}$ & 41865 & gi|269122365|ref|YP_003310542.1 & $\begin{array}{l}\text { Methylobacterium } \\
\text { radiotolerans JCM } 2831\end{array}$ & 58845 & gi|170751253|ref|YP_001757513.1 \\
\hline & $\begin{array}{l}\text { Sinorhizobium fredii } \\
\text { NGR234 }\end{array}$ & 59081 & gi|227820170|ref|YP_002824141.1 & $\begin{array}{l}\text { Methylobacterium } \\
\text { sp. } 4-46\end{array}$ & 58843 & gi|170738904|ref|YP_001767559.1 \\
\hline & $\begin{array}{l}\text { Starkeya novella DSM } \\
506\end{array}$ & 48815 & gi|298294348|ref|YP_003696287.1 & $\begin{array}{l}\text { Mycobacterium } \\
\text { smegmatis str. MC2 } 155\end{array}$ & 57701 & gi|1 18472915|ref|YP_885297.1 \\
\hline & $\begin{array}{l}\text { Tepidanaerobacter } \\
\text { sp. Re1 }\end{array}$ & 66873 & gi|332798945|ref|YP_004460444.1 & $\begin{array}{l}\text { Nocardiopsis } \\
\text { dassonvillei subsp. } \\
\text { dassonvillei DSM } 43111\end{array}$ & 49483 & gi|297561288|ref|YP_003680262.1 \\
\hline & $\begin{array}{l}\text { Thermosediminibacter } \\
\text { oceani DSM } 16646\end{array}$ & 51421 & gi|302389988|ref|YP_003825809.1 & $\begin{array}{l}\text { Paracoccus denitrificans } \\
\text { PD1222 }\end{array}$ & 58187 & gi|1 19386102|ref|YP_917157.1 \\
\hline & $\begin{array}{l}\text { Verminephrobacter } \\
\text { eiseniae EF01-2 }\end{array}$ & 58675 & gi|121609190|ref|YP_996997.1 & Polaromonas sp. JS666 & 58207 & gi|91787595|ref|YP_548547.1 \\
\hline \multirow[t]{3}{*}{ DLO1 } & $\begin{array}{l}\text { Anabaena variabilis } \\
\text { ATCC } 29413\end{array}$ & 58043 & gi|75907337|ref|YP_321633.1 & $\begin{array}{l}\text { Polymorphum gilvum } \\
\text { SL003B-26A1 }\end{array}$ & 65447 & gi|328544682|ref|YP_004304791.1 \\
\hline & $\begin{array}{l}\text { Chloroflexus aggregans } \\
\text { DSM } 9485\end{array}$ & 58621 & gi|219849032|ref|YP_002463465.1 & $\begin{array}{l}\text { Polynucleobacter } \\
\text { necessarius subsp. } \\
\text { asymbioticus QLW- } \\
\text { PIDMWA-1 }\end{array}$ & 58611 & gi|145589731|ref|YP_001156328.1 \\
\hline & $\begin{array}{l}\text { Coraliomargarita } \\
\text { akajimensis DSM } 45221\end{array}$ & 47079 & gi|294053940|ref|YP_003547598.1 & Pusillimonas sp. T7-7 & 66391 & gi|332284324|ref|YP_004416235.1 \\
\hline
\end{tabular}


Table 1 List of DXR-II and DLO related sequences examined in this study (Continued)

\begin{tabular}{|c|c|c|c|c|c|}
\hline $\begin{array}{l}\text { Coxiella burnetii } \\
\text { CbuG_Q212 }\end{array}$ & 58893 & gi|212211864|ref|YP_002302800.1 & $\begin{array}{l}\text { Rhodopseudomonas } \\
\text { palustris BisB5 }\end{array}$ & 58441 & gi|91978550|ref|YP_571209.1 \\
\hline $\begin{array}{l}\text { Coxiella burnetii } \\
\text { CbuK_Q154 }\end{array}$ & 58895 & gi|212217809|ref|YP_002304596.1 & $\begin{array}{l}\text { Rhodospirillum rubrum } \\
\text { ATCC } 11170\end{array}$ & 57655 & gi|83594471|ref|YP_428223.1 \\
\hline $\begin{array}{l}\text { Coxiella burnetii } \\
\text { Dugway } 5 \mathrm{J108-111}\end{array}$ & 58629 & gi|154707185|ref|YP_001423500.1 & $\begin{array}{l}\text { Spirochaeta } \\
\text { smaragdinae } \\
\text { DSM } 11293\end{array}$ & 51369 & gi|302337774|ref|YP_003802980.1 \\
\hline $\begin{array}{l}\text { Coxiella burnetii } \\
\text { RSA } 331\end{array}$ & 58637 & gi|161830312|ref|YP_001597660.1 & Spirochaeta sp. Buddy & 63633 & gi|325972507|ref|YP_004248698.1 \\
\hline $\begin{array}{l}\text { Coxiella burnetii } \\
\text { RSA } 493\end{array}$ & 57631 & gi|29655123|ref|NP_820815.1 & $\begin{array}{l}\text { Streptomyces } \\
\text { flavogriseus ATCC } 33331\end{array}$ & 40839 & gi|357414986|ref|YP_004926722.1 \\
\hline $\begin{array}{l}\text { Cyanothece sp. } \\
\text { PCC } 7425\end{array}$ & 59435 & gi|220910534|ref|YP_002485845.1 & $\begin{array}{l}\text { Streptomyces sp. } \\
\text { SirexAAcpoE }\end{array}$ & 72627 & gi|345003166|ref|YP_004806020.1 \\
\hline $\begin{array}{l}\text { Cyclobacterium } \\
\text { marinum DSM } 745\end{array}$ & 71485 & gi|343084038|ref|YP_004773333.1 & $\begin{array}{l}\text { Variovorax paradoxus } \\
\text { EPS }\end{array}$ & 62107 & gi|319794630|ref|YP_004156270.1 \\
\hline $\begin{array}{l}\text { Deinococcus } \\
\text { maricopensis } \\
\text { DSM } 21211\end{array}$ & 62225 & gi|320332781|ref|YP_004169492.1 & $\begin{array}{l}\text { Variovorax paradoxus } \\
\text { S110 }\end{array}$ & 59437 & gi|239816446|ref|YP_002945356.1 \\
\hline $\begin{array}{l}\text { Desulfococcus } \\
\text { oleovorans Hxd3 }\end{array}$ & 58777 & gi|158521221|ref|YP_001529091.1 & $\begin{array}{l}\text { Xanthobacter } \\
\text { autotrophicus Pyz }\end{array}$ & 58453 & gi|154244830|ref|YP_001415788.1 \\
\hline
\end{tabular}




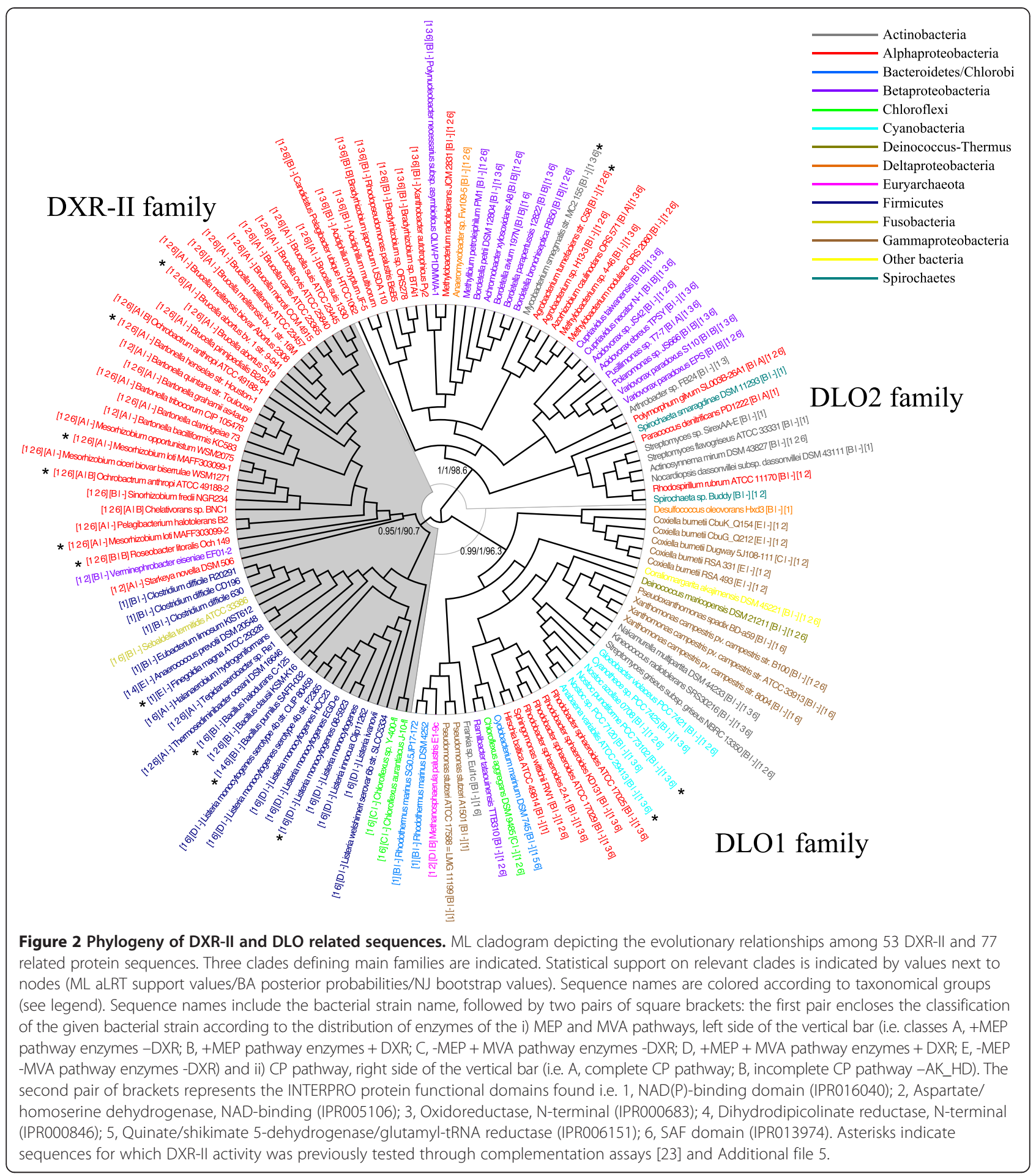

was shared among proteins within families DLO1 and DLO2.

The DXR-II family emerged through functional divergence Phylogenetic analysis revealed the shared ancestry of all functional DXR-II, supporting their common evolutionary origin, and suggested the functional divergence of this family from related oxidoreductases through the acquisition of DXR-II specific biochemical activity. To examine the role of specific amino acid substitutions in functional specialization of DXR-II protein sequences, two different statistical approaches under a ML framework were followed. The first one permits the detection of 
amino acid sites subjected to different evolutionary rates between families under examination, i.e., highly conserved in a family but variable in the other (type-I functional divergence) [27]. The second approach relies on site-specific shifts of amino acid physiochemical properties in positions otherwise highly conserved in each family (type-II functional divergence) [28].

Given the ML tree topology (Figure 2), the ML estimates of the theta $(\theta)$ coefficients for type-I functional divergence between the DXR-II family and families DLO1 and DLO2 were statistically significant in both cases (Table 2). This implies that structural and/or functional selective constraints at some sites have shifted significantly after the divergence of DXR-II from both DLO families. In contrast, the corresponding tests did not support type-II functional divergence (Table 2). Moreover, 28 and 34 specific amino acid residues, including 8 and 11 with high posterior probabilities, were predicted as responsible for type-I functional divergence of DXR-II from DLO families 1 and 2, respectively (Table 2). Interestingly, seven sites detected as key for functional divergence were shared in analyses between the DXR-II family and both the DLO1 and DLO2 families.

These sites were mapped onto the corresponding amino acid sequence alignment (Additional file 1 and Additional file 6: Table S1). At many of these sites, amino acid residues are highly conserved in DXR-II sequences, but are variable in the DLO1 (e.g. positions 161 and 429 in B. melitensis biovar abortus 2308 DXR-II), the DLO2 (e.g. positions 210, 248 and 324), or both the DLO1 and the DLO2 (e.g. positions 35, 64, 118, 121, 122, 133, 197, 229, 250, 291, 320, 330, 346, 351, 353, $413,428,429,432)$ families, likely reflecting a change in their functional roles. Some apparently represented minor changes, as they involved amino acids with similar physicochemical features (e.g. positions 291 or 428). Some others involved radical amino acid changes, such as position 121, occupied by the highly conserved Gly in DXR-II proteins, but also by the unrelated Ala and Ser amino acids in DLO1 and DLO2 proteins. Another example is position 229, filled by the absolutely conserved polar amino acid Thr in DXR-II proteins, but replaced by the highly hydrophobic Leu, Ile and Val amino acids in DLO1 or the physicochemically unrelated Pro, Ser and Ala residues in DLO2. Likewise, position 250, with a basic polar His found in all but four DXR-II proteins was replaced by different hydrophobic amino acids, and finally position 351, with a conserved Val in most DXR-II proteins was substituted by different physicochemically unrelated amino acids in DLO1 and DLO2 proteins.

To gain further insights into their putative functional impact, the amino acid changes detected as related to functional divergence of DXR-II were mapped onto the three-dimensional structure of B. melitensis biovar abortus 2308 DXR-II in its apo form and in complex with the competitive inhibitor fosmidomycin (Figure 3) [26]. Predicted sites were mostly distributed through the middle catalytic domain, but some were also found in the $\mathrm{COOH}$-terminal and NH2-terminal NADP-binding domains (Figure 3A). Two predicted sites corresponded to the conserved residues 229 and 320, identified as important for DXR-II activity [26]. Thr229, together with Lys191 and Lys193, serve to anchor fosmidomycin, presumably participating in the proper binding of the substrate (Figure 3B). Arg320 is located in a cavity at the dimer interface and, together with positions Glu174, Phe178 and Tyr322, may be involved in interactions between the two subunits of the DXR-II dimer (Figure 3C).

\section{DXR-Ils show a discontinuous taxonomic, metabolic and phenotypic distribution among eubacteria}

The markedly scattered distribution of sequences belonging to the DXR-II family across higher order eubacterial taxonomic groups was previously observed [23]. In this up-to-date survey, DXR-IIs were found as encoded by the genomes of free-living eubacteria strains mostly from Alphaproteobacteria (26 strains, mainly from the genera Brucella, 11, and Bartonella, 6) and Firmicutes (21 strains, mainly from the genus Listeria, 9). However, genes coding for functional DXR-II representatives were also found in the genomes of three additional distantly related bacterial taxonomic lineages i.e. the Chloroflexi, Betaproteobacteria and Fusobacteria (Figure 2). Within the DXR-II family, Alphaproteobacteria, Firmicutes and Chloroflexi sequences clustered into separate subclades, while the single Betaproteobacteria and Fusobacteria representatives grouped within the Alphaproteobacteria and Firmicutes subclades, respectively (Figure 2).

We examined the distribution of functional DXR-II at lower taxonomical levels. For example, the occurrence of discontinuities was evident when we mapped DXR-II onto a tree depicting the evolutionary relationships of 72 alphaproteobacterial species (Additional file 7) [30]. DXR-II genes could only be found in the genomes of 25 strains among the 64 with fully sequenced genomes represented in the tree. They mainly belong to the order Rhizobiales, although significant hits were also retrieved from other taxonomic ranks, such as Rhodospirillales or Rhodobacteraceae. Within these alphaproteobacterial groups, strains whose genomes contained genes both encoding and not encoding DXR-II and/or DXR-I could be found. Discontinuities in DXR-II distribution could be appreciated with, e.g., the closely related pairs of Rhodospirillales species Magnetospirillum magneticum AMB-1/Rhodospirillum rubrum ATCC 11170 and Acidiphilium cryptum JF-5/Gluconobacter oxydans $621 \mathrm{H}$. More strikingly, we have retrieved a DXR-II 
Table 2 Analysis of functional divergence

\begin{tabular}{|c|c|c|c|}
\hline $\begin{array}{l}\text { Functional } \\
\text { divergence }\end{array}$ & Families & Coefficient $\theta \pm$ SE & Critical amino acid sites $\left(Q_{k}>0.7 ;{ }^{*}, Q_{k}>0.95\right)$ \\
\hline \multirow[t]{2}{*}{ Type I } & $\begin{array}{l}\text { DXR-II vs } \\
\text { DLO1 }\end{array}$ & $\begin{array}{l}\boldsymbol{\theta}_{1}=0.277 \pm 0.045(\mathrm{LRT}= \\
83.233 ; p=7.292 \mathrm{E}-20)\end{array}$ & $\begin{array}{l}\mathbf{3 5}, 46,118,121,146,161^{*}, 176,198^{*}, \mathbf{2 0 5 *}, 218,229,234,237,247^{*}, 265, \mathbf{2 8 2}^{*}, \mathbf{2 9 1}, 297, \\
\mathbf{3 1 0}, 340,342, \mathbf{3 5 1}^{*}, 353^{*}, 376,404^{*}, \mathbf{4 1 0}, 422,424,429\end{array}$ \\
\hline & $\begin{array}{l}\text { DXR-II vs } \\
\text { DLO2 }\end{array}$ & $\begin{array}{l}\boldsymbol{\theta}_{1}=0.253 \pm 0.043(\mathrm{LRT}= \\
114.991 ; \mathrm{p}=7.907 \mathrm{E}-27)\end{array}$ & $\begin{array}{l}\mathbf{3 5}, 47,64,122^{*}, 128,133,197^{*}, 202, \mathbf{2 0 5}, 210,239,248,250^{*}, 253^{*}, 258^{*}, 260, \mathbf{2 8 2}, \mathbf{2 9 1}, \\
296,305, \mathbf{3 1 0}^{*}, 311^{*}, 314,320,324^{*}, 330^{*}, 346, \mathbf{3 5 1} \mathbf{1}^{*}, 359,383^{*}, \mathbf{4 1 0}^{*}, 413,428^{*}, 432\end{array}$ \\
\hline \multirow[t]{2}{*}{ Type II } & $\begin{array}{l}\text { DXR-II vs } \\
\text { DLO1 }\end{array}$ & $\boldsymbol{\theta}_{2}=-0.998 \pm 0.487$ & \\
\hline & $\begin{array}{l}\text { DXR-II vs } \\
\text { DLO2 }\end{array}$ & $\boldsymbol{\theta}_{2}=-1.115 \pm 0.575$ & \\
\hline
\end{tabular}

$\mathrm{p}=$ posterior probability values; SE Standard Error. LRT and resulting $\mathrm{p}$-values are shown in parentheses. Critical amino acid sites detected as related to functional divergence with $Q_{k}>70 \%\left({ }^{*}, Q_{k}>95 \%\right)$ are listed. Seven sites predicted as related to functional divergence of DXR-II from both families DLO1 and DLO2 are indicated in bold. Numbering refers to Brucella melitensis biovar abortus 2308 DXR-II protein sequence.

sequence only in one out of the five examined genomes of strains from Rhodopseudomonas palustris (strain BisB5), a feature perhaps related to the metabolical versatility attributed to this species [31] (Additional file 7). A similar patchy distribution of DXR-II was observed when DXR-II and DXR-I were mapped onto a phylogeny of Firmicutes (Additional file 8) [32].

Searches for enzymes of the MEP and MVA pathways of IPP and isoprenoid biosynthesis were also performed (Additional file 6: Table S2). The 51 DXR-II-containing

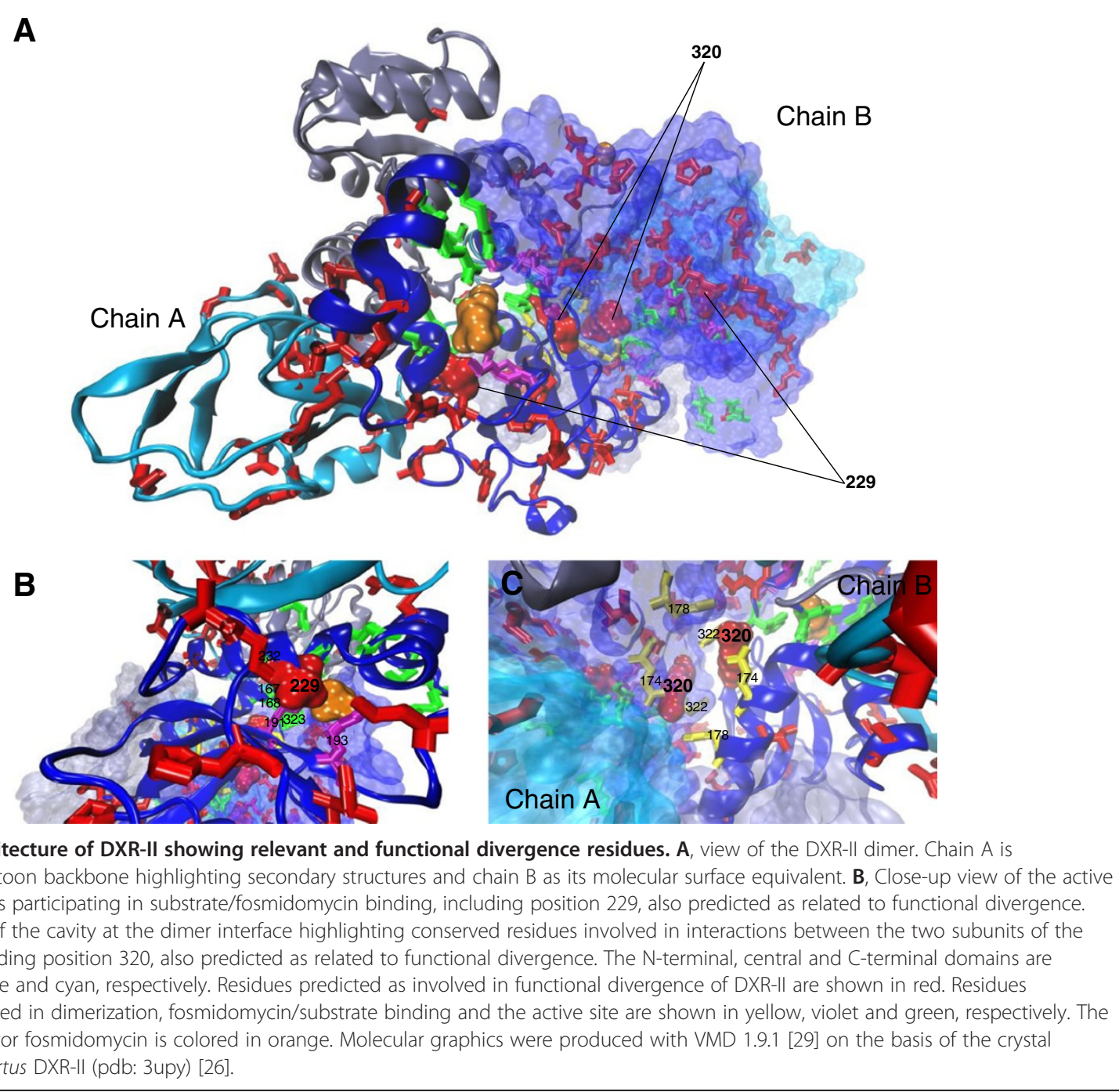


eubacterial strains were classified according to the distribution of enzymes of these pathways, revealing the occurrence of multiple patterns (Figure 2 and Additional file 6: Table S3). The majority of surveyed eubacterial genomes contained genes coding for enzymes of the MEP pathway, but a significant number of them had lost one or more of these enzymes. DXR-I would have been preferentially lost among Alphaproteobacterial strains, but some losses were also found in Firmicutes and Chloroflexi (class A). These species would then exclusively rely on DXR-II for IPP biosynthesis through the MEP pathway. A group, mainly composed of Firmicutes strains showed genes encoding both DXR-II and DXR-I (class B). A significant number of genomes also encoded for enzymes of the MVA pathway. Some of these strains would then use solely the MVA pathway for isoprenoid biosynthesis, such as the two Chloroflexi representatives (class C). DXR-II activity has been experimentally shown from one of these strains, Chloroflexus auranticus J-10-fl, by complementation assays (Additional file 5). Most of them also have a complete and functional MEP pathway, such as Listeria monocytogenes (class D) [6]. Finally, in the genomes of two Firmicutes strains (Anaerococcus prevotii DSM 20548 and Finegoldia magna ATCC 29328) no genes encoding enzymes from the MEP (apart from DXR-II) or the MVA pathways could be found (class E). Interestingly however, DXR-II activity had been confirmed experimentally for the latter [23].

Similarly, the distribution of DXR-II was compared to that of enzymes of the CP pathway of amino acid biosynthesis. The CP represents three enzymatic steps. The first is the phosporylation of aspartate, carried out by AK leading to $\beta$-aspartyl-phosphate, which in turn is oxidized by an ASDH to aspartate semialdehyde. Subsequently, HD catalyses the reduction of aspartate betasemialdehyde into homoserine, in the third and last step of the $\mathrm{CP}$ pathway (Figure 1). The evolutionary diversification of enzymes of the $\mathrm{CP}$ in bacteria is known to have been shaped by gene duplication and fusion events, resulting in bifunctional AK_HD proteins [33]. Most genomes of the 51 DXR-II-containing strains encoded AK and HD. The genomes of five strains also showed bifunctional $A K_{-} H D$ genes, while the genomes of only three Alphaproteobacteria strains encoded for ASDH and were believed to have functional CP (class B) (Figure 1 and Additional file 6: Table S3). However, none of the genomes of DXR-II-containing strains encoded the complete set of enzymes of the $\mathrm{CP}$ (class A, AK, HD, AK_HD and ASDH).

We next examined the distribution of biological properties across DXR-II-containing bacterial strains. For this purpose, we projected the data contained in the NCBI's Microbial Organism Information Page onto the original set of 1489 bacterial strains, after correcting for ambiguities and redundancies. The database, available for download at ftp://ftp.ncbi.nlm.nih.gov/genomes/ genomeprj_archive/, included categories related to the ecological requirements of the organism (e.g. habitat, oxygen requirement, salinity, temperature range, optimal temperature), morphological features (e.g., shape, arrangement, endospores and motility) and additional phenotypic traits (e.g., Gram stain, dinucleotide GC content, genome size and pathogenicity). The distribution of properties across DXR-II- and non DXR-II-containing eubacterial strains is shown in Table 3. To test whether any of these biological properties were differentially represented in the subset of 51 eubacterial strains containing DXR-II regarding the remaining non-DXR-II harbouring strains, we performed Fishers' exact tests. According to these tests, none of the categories related to the ecological requirements of the organism showed a biased representation among DXR-II-containing strains, suggesting that these organisms may not live in shared habitats. A similar unbiased pattern of distribution was found for additional morphological and phenotypic features (Table 3). Only the category "pathogenic in animals" showed a significant overrepresentation among DXR-II -containing strains (Table 3). Similarly, for quantitative properties, such as genome size, GC content and optimal growth temperature, a Student's T test was performed to assess significance of the differences between means. Again, none of the tests were significant (Table 3).

\section{Comparative sequence-based analysis of HGT in DXR-II evolution}

The markedly discontinuous phylogenetic distribution shown by DXR-II might be explained by recurrent events of HGT occurring between unrelated bacterial strains. So long as the DXR-II sequence retains sequence features of the donor strain significantly distinct from that of the genome of the recipient strain, they could be inferred as being acquired by HGT. Consequently, comparative nucleotide sequences analyses of DXR-II against their host genomes could yield clues about their origin and the putative role of HGT in the distribution of DXR-II across eubacteria.

Several methods and criteria were applied to identify signatures of HGT (please see Methods for a complete description). Firstly, GC content at the three codon positions, as well as the total, was estimated. As previously observed [34,35], GC content was relatively constant among genes of a particular species' genomes, although displaying wide variation among species (Additional file 6: Table S4). This was particularly evident at the third codon position, as the majority of these sites are synonymous and, consequently, differences due to mutational biases are higher. In contrast, the first and second codon positions appear to be more conserved between genomes and 
Table 3 Distribution of biological properties in DXR-II and non-DXR-II containing bacterial strains and statistical tests of enrichment

\begin{tabular}{|c|c|c|c|c|}
\hline \multirow{2}{*}{\multicolumn{2}{|c|}{ Biological properties }} & \multicolumn{2}{|c|}{ Number of strains } & \multirow[t]{2}{*}{$p$-value } \\
\hline & & DXR-II & Non-DXR-II & \\
\hline \multirow[t]{6}{*}{ Habitat } & & 41 & 1166 & \\
\hline & Host-associated & 18 & 383 & 0.36 \\
\hline & Multiple & 16 & 330 & 0.33 \\
\hline & Specialized & 3 & 148 & ND \\
\hline & Terrestrial & 2 & 94 & ND \\
\hline & Aquatic & 2 & 211 & ND \\
\hline \multirow[t]{4}{*}{ Oxygen Req } & & 39 & 1137 & \\
\hline & Facultative & 15 & 404 & 0.76 \\
\hline & Aerobic & 15 & 413 & 0.88 \\
\hline & Anaerobic & 9 & 284 & ND \\
\hline \multirow[t]{3}{*}{ Salinity } & & 7 & 245 & \\
\hline & Non-halophilic & 6 & 171 & ND \\
\hline & Moderate halophilic & 1 & 30 & ND \\
\hline \multirow[t]{3}{*}{ Temp. range } & & 38 & 1202 & \\
\hline & Mesophilic & 36 & 1013 & 0.64 \\
\hline & Thermophilic & 2 & 107 & ND \\
\hline Optimal temp. ${ }^{a}$ & & $38.61(18)$ & $41.21(555)$ & 0.27 \\
\hline Genome Size $^{a}$ & & $3.73(48)$ & $3.59(1456)$ & 0.50 \\
\hline GC Content ${ }^{a}$ & & $48.23(45)$ & $48.63(1193)$ & 0.84 \\
\hline \multirow[t]{6}{*}{ Shape } & & 43 & 1239 & \\
\hline & Rod & 29 & 794 & 0.90 \\
\hline & Coccobacillus & 6 & 21 & ND \\
\hline & Coccus & 5 & 188 & ND \\
\hline & Filament & 2 & 20 & ND \\
\hline & Short rod & 1 & 2 & ND \\
\hline \multirow[t]{6}{*}{ Arrangment } & & 35 & 899 & \\
\hline & Singles & 17 & 501 & 0.77 \\
\hline & Pairs & 9 & 209 & ND \\
\hline & Chains & 4 & 107 & ND \\
\hline & Groups & 3 & 3 & ND \\
\hline & Filaments & 2 & 22 & ND \\
\hline \multirow[t]{3}{*}{ Endospores } & & 18 & 626 & \\
\hline & Yes & 6 & 121 & ND \\
\hline & No & 12 & 505 & 0.71 \\
\hline \multirow[t]{3}{*}{ Motility } & & 27 & 947 & \\
\hline & Yes & 22 & 579 & 0.37 \\
\hline & No & 5 & 365 & ND \\
\hline \multirow[t]{3}{*}{ Gram Stain } & & 39 & 1050 & \\
\hline & - & 22 & 704 & 0.60 \\
\hline & + & 17 & 344 & 0.35 \\
\hline
\end{tabular}

Table 3 Distribution of biological properties in DXR-II and non-DXR-II containing bacterial strains and statistical tests of enrichment (Continued)

\begin{tabular}{llccc}
\hline Pathogenic in & & 42 & 1008 & \\
& Animal & 15 & 181 & $\mathbf{0 . 0 4}$ \\
& Human & 14 & 264 & 0.50 \\
& No & 13 & 521 & 0.11 \\
\hline
\end{tabular}

P-values resulting from Fisher's exact tests are shown for categories represented in at least 10 bacterial strains. Test significant at $p<0.05$ is shown in bold type. ${ }^{a}$, for these quantitative properties, the average value (number of strains is shown between parentheses) and p-values resulting from Student's T tests performed to assess significance of the differences between means are shown.

are, consequently, less informative (Additional file 6: Table S4). The GC contents of all DXR-II coding sequences were compared to the mean for all genes encoded by the corresponding genomes. DXR-II from both Chloroflexi representatives and the single Fusobacteria representative Sebaldella termitidis ATCC 33386 showed significantly lower GCt and GC3 content regarding the respective mean for all genes in the genome (Additional file 6: Table S4). A fourth bacterial strain, Rhizobium NGR234, showed higher GCt and GC3 content (Additional file 6: Table S4).

Secondly, we examined for biases in dinucleotide relative frequencies, a remarkably stable property of the DNA of an organism claimed to constitute a 'genomic signature' that can discriminate sequences from different organisms [36]. We focused on the dinucleotide biases at third and first $(3: 1)$ codon positions, which are less sensitive to selective constrains [37]. Consequently, the 3:1 dinucleotide frequencies were calculated for all DXRII coding sequences and for the entire set of genes in the corresponding genomes. They both showed significant variation across organisms, and therefore could be used as such genomic signatures. Significance of the differences between DXR-II genes and their genomes were examined by calculating the dinucleotide relative abundance difference or $\sigma$ difference (Additional file 6: Table S5) [36]. Pairwise co-variation was further assessed through the Spearman and Kendall rank tests (Additional file 6: Table S5). In all but one example, both Spearman's $\rho$ and Kendall's $\tau$ correlation coefficients indicated strong positive correlation. An exception was provided by Halanaerobium hydrogeniformans, which showed negative correlation. All tests revealed significant covariation of 3:1 dinucleotide frequencies of DXR-II with the frequencies of the corresponding genomes, contrary to the expectations of HGT.

Next, we estimated relative synonymous codon usages (RSCU) values, which provide with a simple effective measure of synonymous codon usage bias. Differences in RSCU between DXR-II genes and all other genes in each corresponding genome were assessed by means of $x^{2}$ 
tests (Additional file 6: Table S6) [34]. Chloroflexi strains and S. termitidis ATCC 33386 showed the higher $\chi^{2}$ statistic values, revealing higher variation. However, none of the tests was significant, indicating that DXR-II genes have a codon usage patterns consistent with that of their corresponding genomes, and therefore unlikely to reflect HGT.

Finally, we examined the degree of bias in codon usage of DXR-II genes towards the codon usage of the most expressed genes by comparing Codon Adaptation Index (CAI) values. A significant deviation from the average CAI of the genome was found in strains of Chloroflexi and S. termitidis ATCC 33386 (Additional file 6: Table S7).

\section{Discussion and conclusions}

The structural and functional diversity of isoprenoids correlates with the existence of a wide biochemical and genetic plasticity for their biosynthesis [17]. In eubacteria, this is commonly achieved through the use of alternative metabolic pathways and enzymatic steps in specific lineages. Interesting examples are provided by HMGR and IDI, which are encoded by at least two distinct gene families in bacteria. In this paper we focus in DXR-II, recently characterized as an alternative family to DXR-I in performing the second step of the MEP pathway of isoprenoid biosynthesis in a selected group of eubacteria [23].

Apart from the NAD-binding domain with a core Rossmann-type fold found at the N-terminal region of all oxidoreductases, no significant similarity at the sequence level was observed between DXR-I and DXR-II to infer homology [23]. Correspondingly, the recent determination of the DXR-II crystal structure showed only slight structural relationship with DXR-I proteins and revealed a unique arrangement of the active site [26]. Examples of enzymes catalyzing identical reactions through the same catalytic mechanisms but showing structurally unrelated active sites are known outside the isoprenoid field [38-41]. In some of these though, key catalytic residues may be conserved between functionally redundant enzymes, as also reported for DXR-I and DXR-II [26]. DXR-I and DXR-II likely represent analogous genes that evolved redundant biochemical functions through mechanistic convergence.

Our results support the emergence of the DXR-II family through type I, but not type II, functional divergence from DLO1 and DLO2 families of previously uncharacterized oxidoreductases. These data suggest that DXR-II acquired additional structural and/or functional constraints rather than shifted constraints in amino acids that were already ancestrally constrained. Amino acid changes critical for functional divergence and acquisition of DXR-II biochemical activity were predicted, many of them corresponding to positions highly conserved in
DXR-II, but otherwise variable in DLO1 and/or DLO2. Interestingly, two of these predicted amino acids, Thr229 and Arg320, had been previously identified for their role in fosmidomycin/substrate binding and in dimerization, respectively [26], suggesting that functional shifts in a limited number of amino acid positions could be at the origin of the acquisition of DXR-II biochemical activity.

It could be assumed that the MEP pathway is the ancestral route for IPP and isoprenoid biosynthesis in eubacteria, including the membrane-associated hopanoids, which are among the oldest known biomolecules [42]. The entire set of genes encoding for enzymes involved in the MEP pathway, including DXR-I, has been found widespread in all eubacterial taxonomic groups [5]. In a significant number of DXR-II-containing eubacterial genomes (31), including those from closely related strains, DXR-I has been lost. This raises the question of how DXR-II evolved in DXR-I containing strains, as acquisition of redundant biochemical activities should not be favoured by evolution. The DXR-II family could have emerged under an ecological context that conferred a selective advantage to the emergence and maintenance of a functionally redundant enzyme, e.g. when gene dosage is selectively advantageous. Due to the wide and diverse functions played by isoprenoids and their essential role for cell viability, critical situations in which their biosynthesis was absolutely required may have occurred multiple times throughout eubacterial evolution. Emergence of the DXR-II family should have occurred at an early time in evolution, as supported by the scattered distribution of DXR-II and related oxidoreductases from DLO1 and DLO2 families in distantly related lineages of eubacteria. After relaxation of that burst in selective constraints for isoprenoid biosynthesis, some strains could then have lost one redundant enzyme, commonly DXRII, which shows less catalytic activity in vitro [26]. In addition, maintenance of DXR-II, which shows less sensitivity to inhibition by fosmidomycin than DXR-I [26], might have provided a selective advantage in bacterial strains sharing the same ecological niches as those naturally producing the antibiotic (e.g. Streptomyces species [43]).

The taxonomic distribution of DXR-II across eubacteria showed a marked discontinuity, which was also verified at the metabolic and phenotypic level. Although most genes encoding DXR-II were found in eubacteria with the MEP pathway, their occurrence was not linked to a unique pattern of distribution of enzymes of the MEP or MVA pathways. Similarly, HD, the oxidoreductase family that showed the highest level of similarity with DXR-II, was found in most DXR-II-containing bacterial strains, but not all. In addition, examination of the distribution of biological properties across DXR-II-containing 
strains showed maintenance of DXR-II in the genomes was not linked to a unique pattern of ecological or phenotypic traits. The only exception was 'pathogenic in animals', significantly enriched among DXR-II-containing strains, reflecting the occurrence of DXR-II among pathogenic strains of Brucella, Bartonella, Listeria and Clostridium [44-47].

The outstanding phylogenetic discontinuity in DXR-II distribution across eubacteria could be explained through two alternative, though not mutually exclusive, evolutionary mechanisms, i.e., gene gain through HGT or gene loss. HGT is known to have shaped the evolution of multiple metabolic pathways, including IPP and isoprenoid biosynthesis $[8,24,48]$. However, a unique event of HGT cannot properly explain DXR-II phylogeny. According to our phylogenetic analysis, such HGT events should instead have occurred at different time points throughout eubacterial evolution, e.g. between the Alphaproteobacteria and Firmicutes phyla, between the Alphaproteobacteria and Betaproteobacteria classes within the proteobacteria phylum, between Firmicutes and specific Chloroflexi strains or between Firmicutes and specific Fusobacteria. More recently, HGT should also have occurred between closely related Alphaproteobacteria or Firmicute strains. If this was the case, HGT events should have left a signature of atypical sequence features in DXR-II genes, provided they were recent enough and occurring between distantly taxonomically related donor and acceptor bacterial strains $[34,35]$. Weak signatures of HGT were found only in Chloroflexi and the Fusobacterium S. termitidis ATCC 33386 at the level of GC content and CAI values. However, no biases in dinucleotide frequencies or codon usage were observed in any strain comparison. These results suggested that HGT events were not at the origin of all discontinuities, or were so ancient that DXR-II genes ameliorated their sequence to specific base composition and codon usage of the host genome, making them indistinguishable from ancestral sequences $[34,35]$.

Consequently, although old episodic events of HGT cannot be excluded, the alternative hypothesis of recurrent DXR-II (or eventually DXR-I) gene loss is more likely to explain DXR-II phylogeny. This mechanism has been traditionally considered less parsimonious, as it involves a complex ancestor and gene loss events occurring independently at multiple evolutionary lineages. However, recent works suggests that, on average, gene loss might be a more likely event than gene gain through HGT [49-51].

The DXR-I/DXR-II model constitutes an exceptional natural model to experimentally test the emergence and maintenance of redundant gene function between nonhomologous genes as a result of convergent evolution, as opposed to their emergence from intragenomic duplicates, or paralogs. Furthermore, our results highlight the importance of the functional characterization of evolutionary shortcuts in isoprenoid biosynthesis for screening specific antibacterial drugs and for regulating the production of isoprenoids of human interest.

\section{Methods}

\section{Sequence and phylogenetic analysis}

Sequence databases from the whole sequenced genomes of 1489 bacterial strains were downloaded from the NCBI. Orthologs of enzymes from the MEP and MVA pathways for IPP biosynthesis, as well as for enzymes of the CP of amino acid biosynthesis (Figure 1), were defined as the best reciprocal hits resulting from all-against-all local BLASTP-searches with an E-value cutoff of $1 \mathrm{E}-5$ and a bit score cutoff of 50 [52] using selected previously characterized sequences as queries (Additional file 6: Table S2). Only hits corresponding to full-length sequences were considered. Resulting hits were scanned for the presence of INTERPRO domains.

Phylogenetic analysis was performed on the basis of an alignment of protein sequences obtained using MUSCLE [53]. Maximum Likelihood (ML) phylogenetic reconstruction was carried out in PhyML v3.0 [54] using the LG protein evolution model [55] and heterogeneity of amino acid substitution rates corrected using a $\gamma$ distribution (G) with eight categories plus a proportion of invariant sites (I), selected by ProtTest v2.4 as the best-fitting amino acid substitution model according to the Akaike information criterion [56]. Starting phylogenetic trees were constructed using the modified program BIONJ. Tree topology searching was optimized using the subtree pruning and regrafting option. The statistical support of the retrieved topology was assessed using the Shimodaira-Hasegawa-like approximate likelihood ratio test (aLRT) [57].

Bayesian analysis was conducted in MrBayes v3.1.2 [58] using the WAG model [59] plus G with eight categories plus I. Searches were run using four Markov (MCMC) chains of length 1000000 generations sampling every 100th tree. Once stationary phase was reached (determined by the average standard deviation of split sequences approaching 0 , which reflects convergence of independent tree samples), the first 2500 trees were discarded as burn-in, and a 50\% majority-rule consensus tree was then constructed to evaluate Bayesian posterior probabilities on clades. Neighbor Joining phylogenetic analysis was performed in MEGA 5.0 [60]. The evolutionary distances for Neighbor Joining phylogenetic reconstruction were computed using the Poisson correction method. To obtain statistical support on the resulting clades, a bootstrap analysis with 1000 replicates was performed. Resulting trees were represented and edited using FigTree v1.3.1. 


\section{Analysis of functional divergence}

The analysis of functional divergence was performed using DIVERGE v2.0 [61]. DIVERGE performs the ML estimation of the theta $(\theta)$ type-I and type-II coefficients of functional divergence, based on the occurrence of altered selective constraints or radical shifts of physicochemical properties, respectively $[27,28]$. $\theta$ value indicates the extent of functional divergence, ranging from 0 , no functional divergence to 1 , representing maximum divergence. Functional divergence can be explicitly tested by comparing the fit of a model allowing for functional divergence versus a null model in which functional divergence is not permitted $(\theta=0)$. A Likelihood Ratio Test (LRT) is then used to examine the significance of differences between the $\operatorname{lnL}$ values of the two nested models (calculated as $2 \Delta \mathrm{LnL}$-twice the difference between their $\operatorname{lnL}$ values) [62]. As the LRT asymptotically follows a $x^{2}$ distribution with a number of degrees of freedom equal to one, i.e. the differences in number of parameters between the models being compared $(\theta)$, a p-value for the fitting of the model accounting for functional divergence can be computed. DIVERGE also uses a site-specific profile to estimate the posterior probabilities $\left(\mathrm{Q}_{\mathrm{k}}\right)$ of individual amino acid sites to be critical for functional divergence.

\section{$\mathrm{G}+\mathrm{C} \%$ content, dinucleotide frequencies, codon usage, and CAI analyses}

The following sequence features i) GC\% content at three codon positions and total (GC1, GC2, GC3 and GCt), ii) dinucleotide frequencies at 3:1 codon sites (third base and first base of the succeeding codon) and iii) the relative synonymous codon usages (RSCU) were extracted for individual DXR-II sequences and the rest of genes in the corresponding genomes through PERL and R scripts using cpan and bioperl modules. Codon Adaptation Indexes (CAI) [63] for individual genes and genomes were calculated using the method depicted in [64] as implemented in DAMBE software [65]. Comparative analyses of these sequence features between DXR-II genes and the rest of genes in the genome were performed and differences assessed using different statistical tests.

i) Differences in $\mathrm{G}$ and $\mathrm{C}$ nucleotides content were considered as significant when GC\% deviated by two or more standard errors (SEs) regarding the respective means for all genes in the genome or deviations at first and third codon position were of the same sign and at least one was higher two or more SEs $[35,66]$.

ii) Dinucleotide relative frequencies were calculated as:

$$
\rho_{X Y}^{*}=\frac{f_{X Y}}{f_{X} f_{Y}}
$$

Where $f_{\mathrm{X}}$ denotes the frequency of the mononucleotide $\mathrm{X}$ and $f_{\mathrm{XY}}$ the frequency of the dinucleotide $\mathrm{XY}$. The array of $\rho_{\mathrm{XY}}$ dinucleotide values define the genomic signature of a given species' genome [36]. A simple way to compute differences in dinucleotide relative frequencies between a given gene $(f)$ and the value of the entire genome $(g)$ is through the absolute difference ( $\sigma$ difference) calculated as:

$$
\sigma^{*}(f, g)=\frac{1}{16} \sum_{X Y}\left|\rho_{X Y}^{*}(a)-\rho_{X Y}^{*}(b)\right|
$$

averaged over all 16 dinucleotides [67]. Furthermore, pairwise covariation of the 3:1 dinucleotide differences were assessed using the Spearman's rank correlation coefficient $\rho[68]$ and the Kendall's rank correlation coefficient $\tau$ [69]. Both are nonparametric statistics allowing testing for dependence between two variables.

iii) RSCU provides with a simple effective measure of synonymous codon usage bias, in which codon frequencies are normalized by the frequency expected under the assumption of equal usage of synonymous codons for a given amino acid [70].

$$
\mathrm{RSCU}_{i}=\frac{X_{i}}{\frac{1}{n} \sum_{i=1}^{n} X_{i}}
$$

For synonymous codon $\mathrm{i}$ of an $\mathrm{n}$-fold degenerate amino acid, where $\mathrm{X}$ is the number of occurrences of codon $\mathrm{i}$, and $\mathrm{n}$ the number of synonymous codons encoding for a given amino acid i.e. 1, 2, 3, 4, or 6 . In the absence of any codon usage bias (i.e. all synonymous codons are used equally), the RSCU value would be 1 . A codon that is used less or more frequently than expected will have an RSCU value $<$ or $>$ than 1, respectively. Start, stop and tryptophan codons were excluded from the analysis. To measure bias in synonymous codon usage between DXR-II and all genes in the genome, a $X^{2}$ test of RSCU with 41 degrees of freedom was implemented [34].

iv) CAI was used as an alternative method to determine the degree of bias in the synonymous codon usage of the DXR-II gene regarding the optimal codon usage in the genome $[34,63]$. RSCU was firstly determined for all genes in each species genome, and subsequently used as reference set for the frequencies of the optimal codons in each species [65]. CAI is calculated as

$$
C A I=\frac{C A I_{o b s}}{C A I_{\max }}
$$

where $\mathrm{CAI}_{\mathrm{obs}}$ is the mean of the RSCUs for all codons in a particular gene, and $\mathrm{CAI}_{\max }$ is the mean of the RSCU for the most frequently used codons for an amino acid in a genome. CAI ranges from 0 to 1 , being 1 if the gene only uses the most frequently used synonymous codons in the reference set. Differences in CAI between 
DXR-II and all genes in the genome were considered as significant if higher than 1.5 times the SE.

\section{Availability of supporting data}

The multiple sequence alignment and the phylogenetic tree-files supporting the results of this article have been deposited and are publicly available in the TreeBASE repository under accession numbers: S14611 (http://purl. org/phylo/treebase/phylows/study/TB2:S14611).

\section{Additional files}

Additional file 1: Multiple alignment of 130 DRL and DLO related protein sequences. Positions conserved in $100 \%, 70 \%$ or $40 \%$ of the sequences are shown in black, dark grey and light grey, respectively. Strain names are grouped as DXR-II, DLO1 (grey shadow) and DLO2.

Additional file 2: ML phylogeny of DXR-II and DLO related sequences. ML cladogram depicting the evolutionary relationships among 53 DXR-II and 77 related protein sequences. Statistical support for clades (ML aLRT support values) is indicated next to nodes.

Additional file 3: Bayesian phylogeny of DXR-II and DLO related sequences. Bayesian cladogram depicting the evolutionary relationships among 53 DXR-II and 77 related protein sequences. Statistical support for clades (posterior probabilities) is indicated next to nodes.

Additional file 4: Neighbor Joining phylogeny of DXR-II and DLO related sequences. Neighbor Joining cladogram depicting the evolutionary relationships among 53 DXR-II and 77 related protein sequences. Statistical support for clades (bootstrap values) is indicated next to nodes.

Additional file 5: Complementation of DXR-deficient $E$. coli cells with putative DXR-II sequences from Chloroflexus auranticus J-10-fl. The putative DXR-II sequences were PCR-amplified from genomic DNA and cloned into PJET1.2. The corresponding constructs and positive and negative controls (C-, empty vector; C+, DXR-II (YP_418479.1) from B. melitensis biovar abortus 2308) were used to transform EcAB4-10 cells [23]. Ability of the cloned gene to rescue growth of this DXR-deficient mutant strain was ascertained by monitoring growth on plates either supplemented (+) or not (-) with 1 mM MVA as indicated. 1) YP_001634831.1, 2) YP_001634944.1, and 3) YP_001636771.1.

Additional file 6: Table S1. List of amino acid sites detected as related to functional divergence of DXR-II vs DLO1 and DXR-II vs DLO2.

Table S2. List of sequences used as queries in BLAST searches for enzymes of the MEP, MVA and CP pathway, and the corresponding bacterial strain. Table S3. Distribution of enzymes of the MEP, MVA and the CP pathways across 128 whole sequenced bacterial strains. Table S4. GC content of DXR-I/ genes and corresponding genomes. Table S5. 3:1 relative dinucleotide frequencies at DXR-// genes and their corresponding genomes and statistical tests of co-variation. Table S6. RSCU values at DXR-II genes and their corresponding genomes and statistical tests of independence. Table S7. CAI values for DXR-Il genes and the average for all genes in the corresponding genomes.

Additional file 7: Distribution of DXR-I and DXR-II in

Alphaproteobacteria. The occurrence of DXR-I and DXR-II is represented for alphaproteobacterial strains with full sequenced genomes in a phylogenetic context, according to the robust species tree reported in [30].

Additional file 8: Distribution of DXR-I and DXR-II in Firmicutes. The occurrence of DXR-I and DXR-II is represented for strains with full sequenced genomes in a phylogenetic context, according to the robust species tree for Firmicutes reported in [32].

\section{Abbreviations}

AK: Aspartokinase; ASDH: Aspartate semialdehyde dehydrogenase: CAl: Codon adaptation index; CP: Common pathway; HGT: Horizontal gene transfer; DLO: DXR-II-Like oxidoreductases; DXR: DeoxyXylulose 5-phosphate reductoisomerase; DMAPP: DiMethylAllyl diphosphate; DXR like: DXR-II; HD: Homoserine dehydrogenase; HMGR: Hydroxy-3-Methyl-Glutaryl-CoA Reductase; IDI: IPP isomerase; IPP: Isopentenyl diphosphate; LRT: Likelihood ratio test; MEP: methylerythritol 4-phosphate; MVA: Mevalonate; ML: Maximum likelihood; RSCU: Relative synonymous codon usage; UID: (taxonomy) Unique Identifier.

\section{Competing interests}

The authors declare that they have no competing interests.

\section{Authors' contributions}

LCP and AL collected data. LCP, AL and JPG analysed data. LCP, AL, JPG, FJS, VAA and MRC contributed to the interpretation of the data. LCP and MRC conceived the study and participated in its design. LCP wrote the manuscript with significant contributions by JPG, FJS, VA and MRC. All authors have read and approved the final manuscript.

\section{Acknowledgements}

We thank all our laboratory members for stimulating discussions and suggestions. We thank Derek Taylor and Mario A Fares for critical reading of the manuscript and helpful comments. Financial support for this research was provided by the Spanish Ministerio de Ciencia e Innovación (grants BIO2011-23680 to MRC and BFU2011-25658 to FJS) and Generalitat de Catalunya (2009SGR-26 and XRB) to MRC.

\section{Author details}

'Institute for Plant Molecular and Cell Biology - IBMCP (CSIC-UPV), Integrative Systems Biology Group, C/ Ingeniero Fausto Elio s/n., Valencia 46022, Spain. ${ }^{2}$ Department of Biological Sciences, SUNY-University at Buffalo, North Campus. 109 Cooke Hall, Buffalo, NY 14260, USA. ${ }^{3}$ Centre for Research in Agricultural Genomics (CRAG), CSIC-IRTA-UAB-UB, Campus UAB, Bellaterra, Barcelona 08193, Spain. ${ }^{4}$ Department of Molecular Biology, Universidad de Cantabria and Instituto de Biomedicina y Biotecnología de Cantabria (IBBTEC), UC-CSIC-SODERCAN, Avda. de los Castros s/n, Santander E-39005Cantabria, Spain.

Received: 14 May 2013 Accepted: 16 August 2013

Published: 3 September 2013

\section{References}

1. Croteau R, Kutchan TM, Lewis NG: Secondary Metabolites. In Biochemistry \& Molecular Biology of Plants. Edited by Buchanan WG B, Jones R, American Society of Plant Physiologists; 2000:1250-1318.

2. Daum M, Herrmann S, Wilkinson B, Bechthold A: Genes and enzymes involved in bacterial isoprenoid biosynthesis. Curr Opin Chem Biol 2009, 13(2):180-188.

3. Kuzuyama T, Seto H: Diversity of the biosynthesis of the isoprene units. Nat Prod Rep 2003, 20(2):171-183.

4. Rodríguez-Concepción M, Boronat A: Elucidation of the methylerythritol phosphate pathway for isoprenoid biosynthesis in bacteria and plastids. A metabolic milestone achieved through genomics. Plant Physiol 2002, 130:1079-1089.

5. Lange BM, Rujan T, Martin W, Croteau R: Isoprenoid biosynthesis: the evolution of two ancient and distinct pathways across genomes. Proc Natl Acad Sci U S A 2000, 97(24):13172-13177.

6. Begley M, Gahan CG, Kollas AK, Hintz M, Hill C, Jomaa H, Eberl M: The interplay between classical and alternative isoprenoid biosynthesis controls gammadelta $\mathrm{T}$ cell bioactivity of Listeria monocytogenes. FEBS Lett 2004, 561(1-3):99-104

7. Laupitz R, Hecht S, Amslinger S, Zepeck F, Kaiser J, Richter G, Schramek N, Steinbacher S, Huber R, Arigoni D, et al: Biochemical characterization of Bacillus subtilis type II isopentenyl diphosphate isomerase, and phylogenetic distribution of isoprenoid biosynthesis pathways. Eur J Biochem 2004, 271(13):2658-2669.

8. Boucher Y, Doolittle WF: The role of lateral gene transfer in the evolution of isoprenoid biosynthesis pathways. Mol Microbiol 2000, 37:703-716.

9. Phillips MA, Leon P, Boronat A, Rodriguez-Concepcion M: The plastidial MEP pathway: unified nomenclature and resources. Trends Plant Sci 2008, 13(12):619-623.

10. Jomaa H, Wiesner J, Sanderbrand S, Altincicek B, Weidemeyer C, Hintz M, Turbachova I, Eberl M, Zeidler J, Lichtenthaler HK, et al: Inhibitors of the 
nonmevalonate pathway of isoprenoid biosynthesis as antimalarial drugs. Science 1999, 285(5433):1573-1576.

11. Kuzuyama T, Seto H: Two distinct pathways for essential metabolic precursors for isoprenoid biosynthesis. Proc Jpn Acad Ser B Phys Biol SCi 2012, 88(3):41-52.

12. Lichtenthaler HK: The 1-Deoxy-D-Xylulose-5-Phosphate pathway of Isoprenoid Biosynthesis in plants. Annu Rev Plant Physiol Plant Mol Biol 1999, 50:47-65.

13. Rodríguez-Concepción M, Boronat A: Isoprenoid biosynthesis in prokaryotic organisms. In Isoprenoid Synthesis in Plants and Microorganisms. Edited by Bach TJ, Rohmer M. New York: Springer; 2013:1-16.

14. Rodriguez-Concepcion M: The MEP pathway: a new target for the development of herbicides, antibiotics and antimalarial drugs. Curr Pharm Des 2004, 10(19):2391-2400.

15. Rohdich F, Bacher A, Eisenreich W: Isoprenoid biosynthetic pathways as anti-infective drug targets. Biochem Soc Trans 2005, 33(Pt 4):785-791.

16. Bouvier F, Rahier A, Camara B: Biogenesis, molecular regulation and function of plant isoprenoids. Prog Lipid Res 2005, 44(6):357-429.

17. Perez-Gil J, Rodriguez-Concepcion M: Metabolic plasticity for isoprenoid biosynthesis in bacteria. Biochem J 2013, 452(1):19-25

18. Boucher $Y$, Huber $H$, L'Haridon S, Stetter KO, Doolittle WF: Bacterial origin for the isoprenoid biosynthesis enzyme HMG-CoA reductase of the archaeal orders thermoplasmatales and archaeoglobales. Mol Biol Evol 2001, 18(7):1378-1388.

19. Gophna U, Thompson JR, Boucher Y, Doolittle WF: Complex histories of genes encoding 3-hydroxy-3-methylglutaryl-CoenzymeA reductase. Mol Biol Evol 2006, 23(1):168-178.

20. Kaneda K, Kuzuyama T, Takagi M, Hayakawa Y, Seto H: An unusual isopentenyl diphosphate isomerase found in the mevalonate pathway gene cluster from Streptomyces sp. strain CL190. Proc Natl Acad Sci USA 2001, 98(3):932-937.

21. Barkley SJ, Cornish RM, Poulter CD: Identification of an Archaeal type II isopentenyl diphosphate isomerase in methanothermobacter thermautotrophicus. J Bacterio/ 2004, 186(6):1811-1817.

22. Barkley SJ, Desai SB, Poulter CD: Type II isopentenyl diphosphate isomerase from synechocystis sp. strain PCC 6803. J Bacteriol 2004 186(23):8156-8158.

23. Sangari FJ, Perez-Gil J, Carretero-Paulet L, Garcia-Lobo JM, Rodriguez-Concepcion $M$ : A new family of enzymes catalyzing the first committed step of the methylerythritol 4-phosphate (MEP) pathway for isoprenoid biosynthesis in bacteria. Proc Natl Acad Sci U S A 2010, 107(32):14081-14086.

24. Boucher Y, Douady CJ, Papke RT, Walsh DA, Boudreau MER, Nesbø CL, Case RJ, Doolittle WF: Lateral gene transfer and the origins of prokaryotic groups. Annu Rev Genet 2003, 37:283-328

25. Moreno-Hagelsieb G, Latimer K: Choosing BLAST options for better detection of orthologs as reciprocal best hits. Bioinformatics 2008, 24(3):319-324

26. Perez-Gil J, Calisto BM, Behrendt C, Kurz T, Fita I, Rodriguez-Concepcion M: Crystal structure of brucella abortus deoxyxylulose-5-phosphate reductoisomerase-like (DRL) enzyme involved in isoprenoid biosynthesis. J Biol Chem 2012, 287(19):15803-15809.

27. Gu X: Statistical methods for testing functional divergence after gene duplication. Mol Biol Evol 1999, 16(12):1664-1674.

28. Gu X: A simple statistical method for estimating type-II (cluster-specific) functional divergence of protein sequences. Mol Biol Evol 2006, 23(10):1937-1945.

29. Humphrey W, Dalke A, Schulten K: VMD: visual molecular dynamics. J Mol Graph 1996, 14(1):33-38. 27-38

30. Williams KP, Sobral BW, Dickerman AW: A robust species tree for the alphaproteobacteria. J Bacterio/ 2007, 189(13):4578-4586.

31. Larimer FW, Chain P, Hauser L, Lamerdin J, Malfatti S, Do L, Land ML, Pelletier DA, Beatty JT, Lang AS, et al: Complete genome sequence of the metabolically versatile photosynthetic bacterium rhodopseudomonas palustris. Nat Biotechnol 2004, 22(1):55-61

32. Moreno-Letelier A, Olmedo G, Eguiarte LE, Martinez-Castilla L, Souza V: Parallel evolution and horizontal gene transfer of the pst operon in firmicutes from oligotrophic environments. Int J Evol Biol 2011, 2011:781642.

33. Fondi M, Brilli M, Fani R: On the origin and evolution of biosynthetic pathways: integrating microarray data with structure and organization of the common pathway genes. BMC bioinformatics 2007, 8(Suppl 1):S12.
34. Lawrence JG, Ochman H: Amelioration of bacterial genomes: rates of change and exchange. J Mol Evol 1997, 44(4):383-397.

35. Lawrence JG, Ochman H: Molecular archaeology of the Escherichia coli genome. Proc Natl Acad Sci U S A 1998, 95(16):9413-9417.

36. Karlin S, Burge C: Dinucleotide relative abundance extremes: a genomic signature. Trends Genet 1995, 11(7):283-290.

37. Hooper SD, Berg OG: Detection of genes with atypical nucleotide sequence in microbial genomes. J Mol Evol 2002, 54(3):365-375.

38. Genschel U: Coenzyme a biosynthesis: reconstruction of the pathway in archaea and an evolutionary scenario based on comparative genomics. Mol Biol Evol 2004, 21(7):1242-1251.

39. Gherardini PF, Wass MN, Helmer-Citterich M, Sternberg MJ: Convergent evolution of enzyme active sites is not a rare phenomenon. $\mathrm{J} \mathrm{Mol} \mathrm{Biol}$ 2007, 372(3):817-845.

40. Kulkarni N, Lakshmikumaran M, Rao M: Xylanase II from an alkaliphilic thermophilic Bacillus with a distinctly different structure from other xylanases: evolutionary relationship to alkaliphilic xylanases. Biochem Biophys Res Commun 1999, 263(3):640-645

41. Watanabe S, Yamada M, Ohtsu I, Makino K: alpha-ketoglutaric semialdehyde dehydrogenase isozymes involved in metabolic pathways of D-glucarate, D-galactarate, and hydroxy-L-proline. Molecular and metabolic convergent evolution. J Biol Chem 2007, 282(9):6685-6695.

42. Brocks JJ, Logan GA, Buick R, Summons RE: Archean molecular fossils and the early rise of eukaryotes. Science 1999, 285(5430):1033-1036.

43. Iguchi E, Okuhara M, Kohsaka M, Aoki H, Imanaka H: Studies on new phosphonic acid antibiotics. II. Taxonomic studies on producing organisms of the phosphonic acid and related compounds. J Antibiot (Tokyo) 1980, 33(1):19-23.

44. Guptill L: Bartonellosis. Vet Microbio/ 2010, 140(3-4):347-359.

45. Allerberger $F$, Wagner M: Listeriosis: a resurgent foodborne infection. Clin Microbiol Infect 2010, 16(1):16-23.

46. von Bargen K, Gorvel JP, Salcedo SP: Internal affairs: investigating the brucella intracellular lifestyle. FEMS Microbiol Rev 2012, 36(3):533-562.

47. Wells CL, Wilkins TD: Clostridia: sporeforming anaerobic bacilli. In Medical Microbiology. 4th edition. Edited by Baron S. Galveston (TX); 1996.

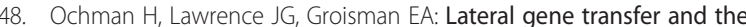
nature of bacterial innovation. Nature 2000, 405(6784):299-304

49. Kunin $V$, Ouzounis CA: The balance of driving forces during genome evolution in prokaryotes. Genome Res 2003, 13(7):1589-1594.

50. Kurland CG, Canback B, Berg OG: Horizontal gene transfer: a critical view. Proc Natl Acad Sci U S A 2003, 100(17):9658-9662.

51. Mirkin BG, Fenner Tl, Galperin MY, Koonin EV: Algorithms for computing parsimonious evolutionary scenarios for genome evolution, the last universal common ancestor and dominance of horizontal gene transfer in the evolution of prokaryotes. BMC Evol Biol 2003, 3:2.

52. Altschul SF, Madden TL, Schaffer AA, Zhang J, Zhang Z, Miller W, Lipman DJ: Gapped BLAST and PSI-BLAST: a new generation of protein database search programs. Nucleic Acids Res 1997, 25(17):3389-3402.

53. Edgar RC: MUSCLE: multiple sequence alignment with high accuracy and high throughput. Nucleic Acids Res 2004, 32(5):1792-1797.

54. Guindon S, Dufayard JF, Lefort V, Anisimova M, Hordijk W, Gascuel O: New algorithms and methods to estimate maximum-likelihood phylogenies: assessing the performance of PhyML 3.0. Syst Biol 2010, 59(3):307-321.

55. Le SQ, Gascuel O: An improved general amino acid replacement matrix. Mol Biol Evol 2008, 25(7):1307-1320.

56. Abascal F, Zardoya R, Posada D: ProtTest: selection of best-fit models of protein evolution. Bioinformatics 2005, 21(9):2104-2105.

57. Anisimova M, Gascuel O: Approximate likelihood-ratio test for branches: a fast, accurate, and powerful alternative. Syst Biol 2006, 55(4):539-552.

58. Ronquist F, Huelsenbeck JP: MrBayes 3: Bayesian phylogenetic inference under mixed models. Bioinformatics 2003, 19(12):1572-1574.

59. Whelan S, Goldman N: A general empirical model of protein evolution derived from multiple protein families using a maximum-likelihood approach. Mol Biol Evol 2001, 18(5):691-699.

60. Tamura K, Dudley J, Nei M, Kumar S: MEGA4: Molecular Evolutionary Genetics Analysis (MEGA) Software Version 4.0. Mol Biol Evol 2007 24(8):1596-1599.

61. Gu X, Vander Velden K: DIVERGE: phylogeny-based analysis for functionalstructural divergence of a protein family. Bioinformatics 2002, 18(3):500-501.

62. Goldman N, Yang Z: A codon-based model of nucleotide substitution for protein-coding DNA sequences. Mol Biol Evol 1994, 11(5):725-736. 
63. Sharp PM, Li WH: The codon Adaptation Index-a measure of directional synonymous codon usage bias, and its potential applications. Nucleic Acids Res 1987, 15(3):1281-1295.

64. Xia X: An improved implementation of codon adaptation index. Evol Bioinform Online 2007, 3:53-58.

65. Xia X, Xie Z: DAMBE: software package for data analysis in molecular biology and evolution. J Hered 2001, 92(4):371-373.

66. Garcia-Vallve S, Romeu A, Palau J: Horizontal gene transfer in bacterial and archaeal complete genomes. Genome Res 2000, 10(11):1719-1725.

67. Karlin S: Detecting anomalous gene clusters and pathogenicity islands in diverse bacterial genomes. Trends Microbiol 2001, 9(7):335-343.

68. Spearman C: The proof and measurement of association between Two things. Am J Psychol 1904, 15(1):72-101.

69. Kendall MG: A new measure of rank correlation. Biometrika 1938, 30(1-2):81-93.

70. Sharp PM, Tuohy TM, Mosurski KR: Codon usage in yeast: cluster analysis clearly differentiates highly and lowly expressed genes. Nucleic Acids Res 1986, 14(13):5125-5143.

doi:10.1186/1471-2148-13-180

Cite this article as: Carretero-Paulet et al:: Evolutionary diversification

and characterization of the eubacterial gene family encoding DXR type

II, an alternative isoprenoid biosynthetic enzyme. BMC Evolutionary

Biology 2013 13:180.

\section{Submit your next manuscript to BioMed Central and take full advantage of:}

- Convenient online submission

- Thorough peer review

- No space constraints or color figure charges

- Immediate publication on acceptance

- Inclusion in PubMed, CAS, Scopus and Google Scholar

- Research which is freely available for redistribution 